Aizawa, T. 287

Albright, J. 249

Anseth, K.S. 274

Barati, M.T. 281

Beck, D.J. 281

Bereiter, D.A. 227

Block, J.A. 202

Cho, T.-J. 287

Chu, T.M.G. 311

Cruceta, J. 287

Dodds, J.C. 281

Dubner, R. 239

Einhorn, T.A. 287

English, A.W. 185, 211

Feinberg, S.E. 311

Feitelson, J.B.A. 281

Fleming, J.T. 281

Fried, J.L. 187

Gerstenfeld, L.C. 287
Glowacki, J. 304

Graves, B.D. 287

Grigg, P. 219

Halloran, J.W. 311

Herring, S.W. 193

Hollister, S.J. 311

Horowitz, M.C. 259

Hurwitz, D.E. 202

Imbe, H. 239

Iwata, K. 239

Kacena, M.A. 259

Kon, T. 287

Konda, S.R. 259

Krebsbach, P.H. 311

Landeau, J.-M. 249

Landesberg, R. 249

Liu, Z.J. 193

Malkani, A.L. 281

Merrel, G.A. 259
Mina, M. 297

Nuttall, M.E. 267

Parameswaran, D. 281

Poshusta, A.K. 274

Puzas, J.E. 249

Reader, M. 211

Ren, K. 239

Schwartz, G. 211

Schwarz, E.M. 249

Soukhova, G.K. 281

Stohler, C.S. 185

Sumner, D.R. 202

Tallents, R. 249

Voor, M.J. 281

Warren, M.P. 187

Wilson, K.M. 259

Xi, Y. 259

Zhou, Q.-Q. 239

Zou, S. 239

\title{
Subject Index Vol. 169, No. 3, 2001
}

Afferents 219

Androgens 211

Biomaterials 274

Biomimetic tissue engineering, imagebased 311

Bone 202, 281, 304

- degradation 259

- injury, blood flow 281

- mineral density 202

- repair 287

- strain 193

Cartilage 304

Cervical spinal cord 227

Chondrogenesis 287

Complete Freund's adjuvant 239

Condyle 193

Cytokines 249, 259

Degradative pathway 249

Drug discovery 267

Endothelin 281
Epithelial-mesenchymal interactions 297

Evans blue extravasation 239

Fiber type 211

Fos-like immunoreactivity 227

Fracture repair 287

Genomics 267

Inflammation 259

Joint loading 202

- space width 202

Joints 219

Mandibular processes 297

Masseter 211

Mastication 193

Matrix metalloproteinases 249

Meniscus 304

Morphogenesis, mandibular 297

Myosin heavy chain 211

Neurons 219

Norepinephrine 281

Osteoarthritis 202
Osteogenesis 287

Paratrigeminal nucleus 239

Photopolymerization 274

Preprodynorphin gene 239

Proteomics 267

Reconstruction, temporomandibular joint 311

Secreted factors 297

Temporomandibular joint 187, 193, 211, $227,249,259,274,304,311$

- - disorder 187, 259

Three-dimensional prototyping 274

Tissue engineering 274, 304, 311

Transcription factors 297

Transgenic mice 249

Trigeminal Fos protein expression 239

- spinal nucleus 227

Tumor necrosis factor alpha 287

Women, temporomandibular joint disorder 187

\section{KARGER}

(C) 2001 S. Karger AG, Basel

Fax + 41613061234

E-Mail karger@karger.ch

www. karger.com 